\title{
A TEM Study of Precipitates in a Nb Microalloyed Steel During Reheating
}

\author{
Yueling Qin", Bart Kooi ${ }^{* *}$ and Jeff Th. M. De Hosson ${ }^{* *}$ \\ * Department of Physics, University at Buffalo, SUNY, Buffalo, New York 14260 \\ ** Department of Applied Physics, Materials Science Center and Netherlands Institute for Metals \\ Research, University of Groningen, Nijenborgh 4, 9747 AG Groningen, The Netherlands
}

The improvements in mechanical properties of low carbon plate steels can be achieved by the combination of microalloying and controlled thermomechanical processing. The microalloying elements such as $\mathrm{Nb}, \mathrm{Ti}$, and $\mathrm{V}$, facilitate austenite grain refinement and precipitation strengthening of ferrite by controlled formation of precipitates. Multi-microalloying can lead to the formation of compounds with complex chemical compositions, which further influences the mechanical properties of the steels[1-3]. The type of precipitate formed and the sequence of dissolution are controlled by the thermodynamics of the phases and their composition. It was found that the precipitation of $\mathrm{Nb}$ carbonitrides in the $\mathrm{Nb}$ steels was changed by $\mathrm{Ti}$ additions which led to the formation of complex Ti-Nb carbonitrides [1]. The core of such complex particle is based on TiN and has a spherical, cubic or cruciform shape [4]. Many of the cores have caps in the form of epitaxial overgrowths based on $\mathrm{NbC}$. These $(\mathrm{Ti}, \mathrm{Nb})(\mathrm{C}, \mathrm{N})$ carbonitrides are very stable at high temperature and exhibit a cubic shape, therefore $\mathrm{Nb}$ is not fully soluble in the reheating process and remains in Ti-rich $(\mathrm{Ti}, \mathrm{Nb})(\mathrm{C}, \mathrm{N})$ carbonitrides formed during the steel melting process [3]. A very low level of $\mathrm{Ti}$ additions was found to have a large influence on the dissolution behavior and precipitation kinetics of niobium carbonitrides. In this study, we present a TEM investigation on such complex $(\mathrm{Nb}, \mathrm{Ti})(\mathrm{C}, \mathrm{N})$ carbonitrides in the niobium-bearing steel containing $0.003 \mathrm{wt} \% \mathrm{Ti}$.

The $\mathrm{Nb}$-bearing microalloyed steel was supplied by Corus in the form of as-hot rolled plate. $10 \mathrm{~mm}$ cubes were cut from this plate and reheating treatments were performed in the temperature range between 900 and $1250{ }^{\circ} \mathrm{C}$ for $30 \mathrm{~min}$. The reheated samples were then quenched in water to below room temperature. Specimens for TEM were prepared by the conventional method of careful grinding, followed by electropolishing. The specimens were examined with a JEOL 2010 FEG-TEM fitted with a Gatan Imaging Filter (GIF), operating at 200keV. Chemical analysis for the precipitates was performed by using Energy Dispersive x-ray spectroscopy (EDS). The change of titanium to niobium ratio within precipitates was also investigated by performing line-scans across the precipitates with a 1-nm spot size. The GIF was used to acquire elemental maps for niobium, titanium, nitrogen and carbon using the three-window method [5] to show the position and concentration of the elements within the precipitates.

A large number of complex $(\mathrm{Nb}, \mathrm{Ti})(\mathrm{C}, \mathrm{N})$ precipitates were observed in the hot-rolled steel, in spite of the low level of titanium and nitrogen. According to their morphology, there are two types of precipitates. The precipitates with an irregular spherical shape were mostly observed; whereas the type which demonstrated a cuboid (rectangular parallelopiped) morphology was encountered less frequently. In general, both of them were $\mathrm{Nb}$-rich carbonitrides. However, a higher $\mathrm{Ti} / \mathrm{Nb}$ ratio was clearly found in the cuboid precipitates. Most of the observed precipitates ranged in size from 40 to $80 \mathrm{~nm}$, although some of them were more than $100 \mathrm{~nm}$. The cuboid precipitates tended to have a larger size. Although most precipitates showed a low Ti composition, still some precipitates had a quite high $\mathrm{Ti} /(\mathrm{Ti}+\mathrm{Nb})$ ratio, around $0.4 \sim 0.5$, compared to the average value of 0.127 . Line scan 
nano-beam EDS analysis also showed in these precipitates with a high $\mathrm{Ti} / \mathrm{Nb}$ ratio that, there was an even clearly higher $\mathrm{Ti} / \mathrm{Nb}$ ratio at the core than in the brim layer. A clear example is shown in Fig. 1. It should be noted that the effect of a thickness variation in the EDS measurements can be eliminated by calculating the $\mathrm{Ti} / \mathrm{Nb}$ ratio.

In order to understand the dissolution and re-precipitation behavior of these complex carbonitrides during reheating process, we investigated the distribution and morphology of precipitates after reheating. At the reheating temperature of $900^{\circ} \mathrm{C}$, the original precipitates grew to a larger size. In addition, a large number of small precipitates, having sizes ranging from 10 to $20 \mathrm{~nm}$, were observed in this sample. For such small precipitates, EDS is difficult to detect their composition. However, the GIF elemental maps shown in Fig. 2 indicate that they are niobium carbides. Such small $\mathrm{NbC}$ precipitates were not observed either in the hot-rolled steel or the steel reheated at higher temperatures. The complex precipitates started to dissolve when the steel was reheated at $1000^{\circ} \mathrm{C}$, resulting in a smaller average size in this reheating temperature. With increasing the reheating temperature, less precipitates could be observed in the samples. These precipitates tended to become smaller when increasing the reheating temperature $\left(\geq 1000^{\circ} \mathrm{C}\right)$. The EDS analysis also indicated an increase in the ratio of titanium to niobium when compared with the lower temperature. Still many precipitates containing niobium in association with titanium were found in the sample reheated at $1200^{\circ} \mathrm{C}$, which demonstrated a greater thermodynamic stability of the complex precipitates compared to pure $\mathrm{NbC}$.

References

[1] K.J. He et al., Mater. Sci. Eng., A169 (1993) 53.

[2] C. Zhou et al., ISIJ International, 36 (1996) 1397.

[3] S.G. Hong et al., Scripta Mater., 46 (2002) 163.

[4] A.J. Craven et al., Acta Mater., 48 (2000) 3857.

[5] F. Hofer et al., J. Microsc., 184 (1996) 163.

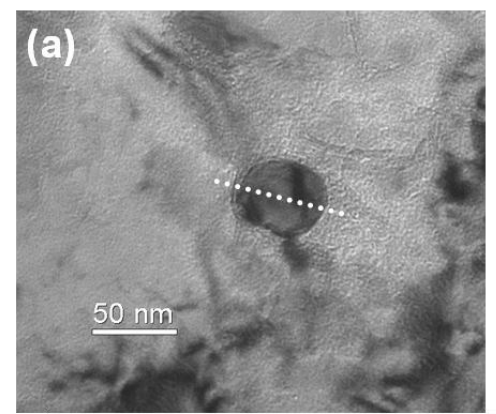

(b)

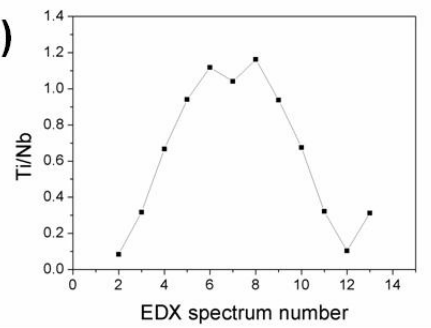

FIG 1. A bright field TEM micrograph of a precipitate in the hot-rolled steel (a) and the line scan profile (b). The electron spot is 1 $\mathrm{nm}$, and the line scan step is $6.8 \mathrm{~nm}$.
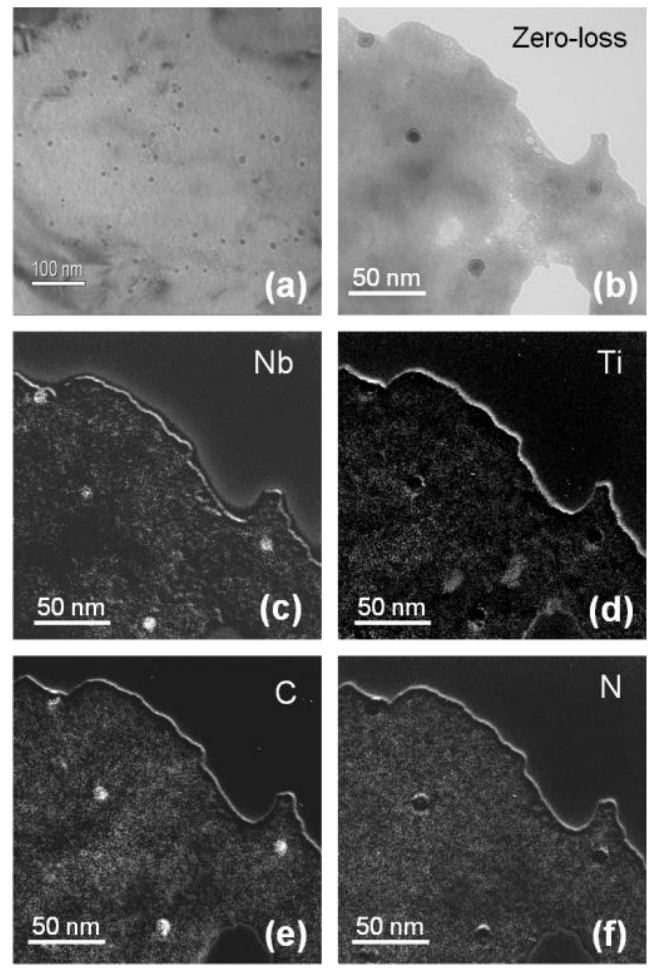

FIG 2. TEM micrographs of very small $\mathrm{NbC}$ precipitates formed in the HSLA steel after $900^{\circ} \mathrm{C}$ reheating. (a) is an overview micrograph with low magnification; (b) is a zero-loss image with higher magnification, and (c)-(f) are the elemental maps using niobium (c), titanium (d), carbon (e) and nitrogen (f), respectively. 